\title{
Reflex Apnea from Laryngeal Chemo-Stimulation in the Sleeping Premature Newborn Lamb
}

\author{
FRANCOIS MARCHAL, ${ }^{(51)}$ BARRY C. CORKE, ${ }^{(52)}$ AND HAKAN SUNDELL ${ }^{(54)}$ \\ Departments of Pediatrics and Anesthesiology, Vanderbilt University School of Medicine, Nashville, Tennessee, USA
}

\begin{abstract}
Summary
The laryngeal chemoreflex was studied during quiet and REM sleep and wakefulness in premature newborn lambs. The response to reflex stimulation with a 5 sec-water infusion was evaluated during $30 \mathrm{sec}$, as \% change in ventilation, heart rate and blood pressure. Apnea, hypertension and bradyjoardia were more pronounced during sleep than during waltefilhess, when arousal was not associated with the stimulation. The response was similar during quiet and REM sleep. Arousal, which occurred in 24 and $31 \%$ of the tests respectively, resulted in a response comparable to that seen during wakefulness. The respiratory drive was evaluated by measurement of the mean inspiratory flow and was found to be decreased during both sleep states when compared to wakefulness. We propose that during sleep in the newborn period there is a decreased ability to respond to asphyxia possibly due to a functional immaturity of the arterial chemoreceptors. This results in a low incidence of arousal and a delayed termination of the pronounced poststimulus apnea resulting from laryngeal chemoreflex stimulation.
\end{abstract}

\section{Speculation}

In the newborn lamb, quiet and REM sleep have been shown to be more vulnerable states than wakefulness to reflex apnea elicited by laryngeal chemoreflex stimulation with water, probably as a reflection of decreased respiratory drive and a failure to arouse. It is possible that reflex apnea during sleep triggered by a variety of mechanisms may play a role in the pathogenesis of Sudden Infant Death Syndrome (SIDS).

The inhibitory effect on respiration of superior laryngeal nerve stimulation was first recognized by Rosenthal in 1862 (43). Several investigators have since studied extensively the reflex elicited by the stimulation of the laryngeal chemoreceptors $(5,6,19,21,22$, $25,26,29,46)$. Stimulation of the laryngeal chemoreflex (LCR) in the unanesthetized animal elicits a multi-organ response: apnea, swallowing, bradycardia, increase in pulmonary and systemic vascular resistances and blood flow redistribution in the dive pattern with preservation of cerebral and myocardial perfusion. The afferent pathway of the reflex lies in the superior laryngeal nerve. Previous reports in anesthetized newborn animals have shown that this reflex apnea can be lethal $(13,26,33,48)$.

SIDS victims usually die during the night, presumably because of failure to recover from apnea during sleep. Both quiet $(2,18$, $20,44)$ and REM sleep $(12,17,18,23,28,48)$ have been implicated as being vulnerable activity states for apnea in the newborn period, especially in premature infants. A recent study in the unanesthetized adult dog has described the depressed arousal response from REM sleep occurring after LCR stimulation (47); however, little is known about the influence of different activity states on the LCR response in newborn animals.

This study was performed in unanesthetized premature newborn lambs in order to evaluate the effects of different activity states on the respiratory and cardiovascular response to laryngeal chemoreflex stimulation. The study lambs were delivered prematurely in order to perform the studies during an age period that more closely resembles the age period when infants frequently have recurrent apnea, and to assure availability of adequate sleep periods for study (23).

\section{MATERIALS AND METHODS}

Instrumentation. Five newborn Dorset lambs were delivered vaginally between 130 and 135 days of gestation, following 3 days of maternal steroid therapy (betamethasone, $12 \mathrm{mg}$ daily) to induce premature parturition (23). Normal gestation for this breed of sheep is 147 days. Birth weight ranged from $2100-3630 \mathrm{~g}$ (mean \pm S.E. $=2830 \pm 284$ ). They were instrumented $1-4$ days after birth under nitrous oxide and chloralose anesthesia with the following procedures: femoral artery and cephalic vein cannulation; side hole tracheostomy performed $4-5 \mathrm{~cm}$ below the larynx; two stainless screw electrodes implanted above the right eyebrow for electrooculogram (EOG); and two additional electrodes on the right temporal area of the skull for electroencephalogram (EEG). The wires were tunneled subcutaneously to the neck. Continuity between the lower and upper part of the trachea was reestablished through a piece of endotracheal tube (Portex, 4-6), allowing the animal, when not studied, to breathe through the upper airway. The lambs were reunited with their mothers within a few hours and 1-3 days were allowed for recovery. Antibiotics (penicillin, $50,000 \mathrm{U} / \mathrm{kgxd}$, streptomycin, $15 \mathrm{mg} / \mathrm{kgxd}$ ) were given for $1 \mathrm{wk}$ after instrumentation. The studies were performed during the second wk after birth. After death, the larynx was inspected with light microscopy to assure that the epithelium was still intact.

Study design. The lambs were always studied in the same cage and they quickly became familiar with this environment. Periods of sleep were usually obtained between $11 \mathrm{AM}$ and 4 PM. Rectal temperature was maintained at $39 \pm 0.5^{\circ} \mathrm{C}$ with the use of external heat or ice packs if required. Before each study, a foley catheter was introduced through the tracheostomy into the upper part of the trachea. The occluding balloon was inflated, allowing retrograde infusion of test solutions into the larynx without leakage of fluid into the lungs. The lambs were breathing spontaneously through a tight fitting endotracheal tube (Portex, 4-6) against a continuous positive airway pressure of $2-4 \mathrm{~cm} \mathrm{H}_{2} \mathrm{O}$ provided by a Baby bird respirator. The respirator was used to supply CPAP to compensate for a decreased functional residual capacity due to endotracheal intubation and, on occasion, to administer intermittent mechanical ventilation, as needed, after prolonged poststimulus apnea.

Respiratory flow was measured through a pneumotachograph (Hewlett Packard 21070B) connected to a differential pressure transducer (Hewlett Packard model 270). Aortic blood pressure was measured with a Statham P 23 ID pressure transducer. Recordings were performed with a Hewlett-Packard 880DS cardiovascular recording system. Electronic integration of the pneumotachograh signal (Respiratory Integrator 8815A) allowed measurement of either tidal or minute volume. Heart rate was integrated from the blood pressure signal with a rate computer (21376A). 
Blood gases were measured with an Instrumentation Laboratory \#213 instrument (Watertown, MA).

Sleep state determination. Three different activity states were determined by behavioral and electrical criteria: (1) Wakefulness (W): lamb standing or lying in resting condition with eyes open. EEG shows a predominant low voltage high frequency activity. (2) Quiet sleep (QS): lamb lying, without apparent activity except for a few gross body movements. Eyes are closed. EEG shows a predominant high voltage low frequency pattern. Rapid eye movements are absent on EOG. (3) Rapid eye movement sleep (REM): lamb lying with eyes closed and frequent small jerky movements of the extremities. Wakefulness-like pattern is seen on EEG and rapid eye movements are present on EOG. During that state, irregular breathing is frequent. No attempt was made to differentiate active from non-active REM sleep.

Evaluation of respiratory drive. During each activity state the mean inspiratory flow (tidal volume/inspiratory time $\mathrm{V}_{\mathrm{T}} / \mathrm{T}_{\mathrm{I}}$ ) was measured and was used as an index of central respiratory drive (35). Inspiratory volume was obtained by electronic integration of the respiratory flow signal and $T_{\mathfrak{r}}$ was measured from the flow signal using a $50 \mathrm{~mm} / \mathrm{s}$ paper speed. Three values were obtained for each lamb's activity state on 3 separate days, each value representing an average of 20 measured breaths.

Evaluation of the response to $L C R$ stimulation. During a well established activity state recorded for at least $2 \mathrm{~min}$ the laryngeal chemoreflex was stimulated by a $5 \mathrm{sec}$ infusion of $1 \mathrm{ml}$ distilled water at body temperature through the foley catheter over the laryngeal area in a retrograde fashion.

Evaluation of the response to $L C R$ stimulation. (a) Respiratory response. Nineteen to thirty reflex stimulations were performed in each lamb during the second wk after birth. The effect on ventilation, recorded as the integrated respiratory volume (top tracing in Fig. 1), was measured for $30 \mathrm{sec}$ after the onset of stimulation.
The response was expressed as \% change from the $30 \mathrm{sec}$ baseline period immediately preceding stimulation. A $30 \mathrm{sec}$ time period was chosen because the apnea and hypoventilation usually lasted beyond the $5 \mathrm{sec}$ stimulation time, and respiration was usually spontaneously restored within $30 \mathrm{sec}$ after the onset of stimulation. The $30 \mathrm{sec}$ ventilation volume $\left(\mathrm{V}_{30}\right)$ was found to correlate with body weight, which ranged from $2.9-5.5 \mathrm{~kg}$. This variable was therefore expressed as $\mathrm{ml} / \mathrm{kg}$.

Evaluation of the response to LCR stimulation. (b) Cardiovascular response. Blood pressure and heart rate were measured 10,20, and $30 \mathrm{sec}$ after the onset of stimulation. The response was expressed as the \% change from the baseline value.

Evaluation of the response to LCR stimulation. (c) Blood gas response. The arterial oxygen and carbon dioxide tensions were determined $20 \mathrm{sec}$ after the onset of stimulation in each activity state on two occasions in each of two lambs.

Evaluation of the response to LCR stimulation. (d) Arousal. Arousal resulting from LCR stimulation was recognized as definite change in behavior: eye opening and gross motor movements or standing up usually associated with a forced inspiration. During quiet sleep, arousal was associated with a change in EEG activity from high voltage, slow waves to low voltage, fast waves; however, transient changes in EEG pattern not associated with behavioral modifications were not considered as arousal. Reflex stimulation during REM sleep invariably was associated with cessation of EOG activity.

Statistical analysis. The results are expressed as mean \pm S.E. The statistical evaluation was done using the mean value for each variable in each lamb's activity state. A protected $t$ test was used to compare one mean with another when a two way analysis of variance showed a significant $F$ ratio in the comparison among activity states (Hewlett Packard 0004l, Program 1500C). This test also permitted comparison of the response among lambs. When a
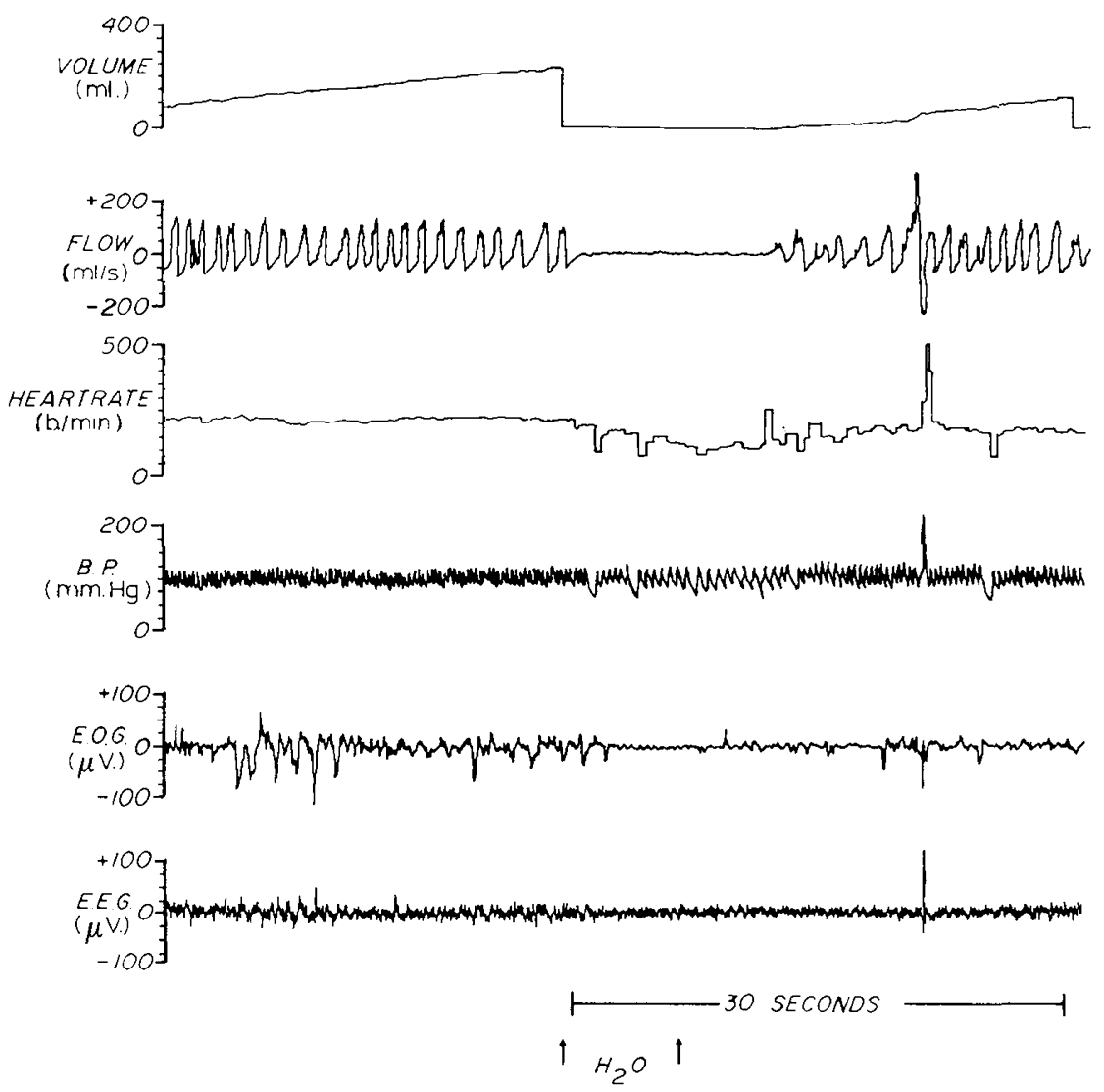

Fig. 1. Recordings from a 1-week-old lamb showing respiratory, heart rate, and blood pressure response to laryngeal chemoreflex stimulation during wakefulness. EEG shows a low voltage high frequency activity, and EOG shows presence of eye movements. One $\mathrm{ml}$ of water was infused into the larynx during $5 \mathrm{sec}$ (arrows). The response was evaluated during $30 \mathrm{sec}$ after the onset of water-stimulation (paper speed $5 \mathrm{~mm} / \mathrm{sec}$ ). 
Table 1. Baseline measurements in five newborn lambs studied during wakefulness, quiet and REM sleep (mean \pm S.E.)

\begin{tabular}{|c|c|c|c|c|c|}
\hline & W & QS & REM & $\begin{array}{c}\text { Comparison } \\
\text { between states }\end{array}$ & $P$ \\
\hline Ventilation volume $(\mathrm{ml} / \mathrm{kg})^{2}$ & $200 \pm 22$ & $161 \pm 13$ & $150 \pm 13$ & $\begin{array}{l}\mathrm{W}>\mathrm{QS} \\
\mathrm{W}>\mathrm{REM}\end{array}$ & $\begin{array}{l}<0.05 \\
<0.01\end{array}$ \\
\hline Heart rate & $244 \pm 10$ & $239 \pm 11$ & $209 \pm 15$ & $\begin{array}{r}\text { W }>\text { REM } \\
\text { QS }>\text { REM }\end{array}$ & $\begin{array}{l}<0.05 \\
<0.05\end{array}$ \\
\hline Systolic blood pressure & $104 \pm 4$ & $97 \pm 4$ & $91 \pm 3$ & $\mathrm{~W}>\mathrm{REM}$ & $<0.01$ \\
\hline Diastolic blood pressure & $62 \pm 4$ & $54 \pm 4$ & $52 \pm 3$ & $\begin{array}{l}\mathrm{W}>\mathrm{QS} \\
\mathrm{W}>\mathrm{REM}\end{array}$ & $\begin{array}{l}=0.05 \\
<0.05\end{array}$ \\
\hline $\begin{array}{l}\text { Mean inspiratory flow } \\
(\mathrm{ml} / \mathrm{kg} / \mathrm{s})^{3}\end{array}$ & $15.5 \pm 1.0$ & $11.8 \pm 0.8$ & $11.3 \pm 1.0$ & $\begin{array}{l}\mathrm{W}>\mathrm{QS} \\
\mathrm{W}>\mathrm{REM}\end{array}$ & $\begin{array}{l}<0.001 \\
<0.001\end{array}$ \\
\hline
\end{tabular}

\footnotetext{
${ }^{\prime}$ Analysis of variance. Only significant differences are indicated.

${ }^{2}$ Measured during $30 \mathrm{sec}$ immediately preceding laryngeal stimulation.

"Tidal volume divided by inspiratory time.
}

significant $F$ ratio was obtained, the least significant difference (LSD) for the protected $t$ value was calculated to compare one mean value with another. A $P$ value less than 0.05 was retained as significant. The comparison of incidence of arousal from quiet and REM sleep was done for each lamb, using Fisher's exact test.

\section{RESULTS}

Baseline measurements. The results of baseline measurements of ventilation, heart rate, systolic and diastolic blood pressure, as well as mean inspiratory flow performed in each activity state is presented in Table 1. The average value of 19-30 determinations for each lamb in each activity state were used to calculate the mean \pm S.E. Ventilation volume was lower during sleep than during wakefulness but there was no difference between the two sleep states. Heart rate and blood pressures were also lower during sleep.

Mean inspiratory flow during basal conditions was lower during sleep as compared to wakefulness $(\mathrm{F}=9.90, P<0.001)$ but there was no difference between quiet and REM sleep.

Laryngeal chemoreflex stimulation. Laryngeal chemoreflex stimulation with distilled water, as described above, resulted in apnea associated with bradycardia and systemic hypertension (Fig. 1).

Respiratory response and arousal. The respiratory response to reflex stimulation was expressed as \% change in $V_{30}$ from baseline. The response during sleep, regardless of arousal, was compared to the response during wakefulness. $F$ ratio for activity states was $7.55, P<0.05$. The respiratory response was significantly greater during either QS $(73.1 \pm 9.5 \%)$ or REM $(64.5 \pm 8.9 \%)$ than during $\mathrm{W}(46.8 \pm 6.2 \%)(\mathrm{LSD}=16.0)(P<0.05)$, but there was no difference between QS and REM. Analyses of the response among lambs showed a significant individual variation $\mathrm{F}=6.69, P<0.01$ for 4 and 18 degrees of freedom.

Arousal associated with the stimulation occurred after $10 / 41$ or $24 \%$ of the stimulations during QS and after $14 / 45$ or $31 \%$ during REM (NS). There was a variable incidence among the lambs and no consistent difference was found between QS and REM. Only one lamb had a significantly different incidence of arousal during sleep $(0 / 5$ during $Q S$ versus $6 / 8$ during REM, $P<0.02$.)

Arousal from QS or REM led to a faster recovery from apnea and, hence, to a reduced respiratory response $(37.5 \pm 5.2 \%)$, which was not different from that observed during W (Fig. 2). In contrast, stimulation not associated with arousal led to a pronounced response, which was not different between QS and REM but, which was significantly different from the response in either wakefulness or sleep with arousal. (F ratio $=42.8, \mathrm{LSD}=21.0, P$ $<0.001$ ).

There was a wide variation in the individual response, as shown by the value of the $F$ ratio comparing the response among lambs (Fig. 2). The most profound response occurred in one lamb that failed to recover $45 \mathrm{sec}$. after the onset of stimulation and required resuscitation with mechanical ventilation in 3 of 7 studies performed during W, 5/10 during QS and 5/9 during REM. This

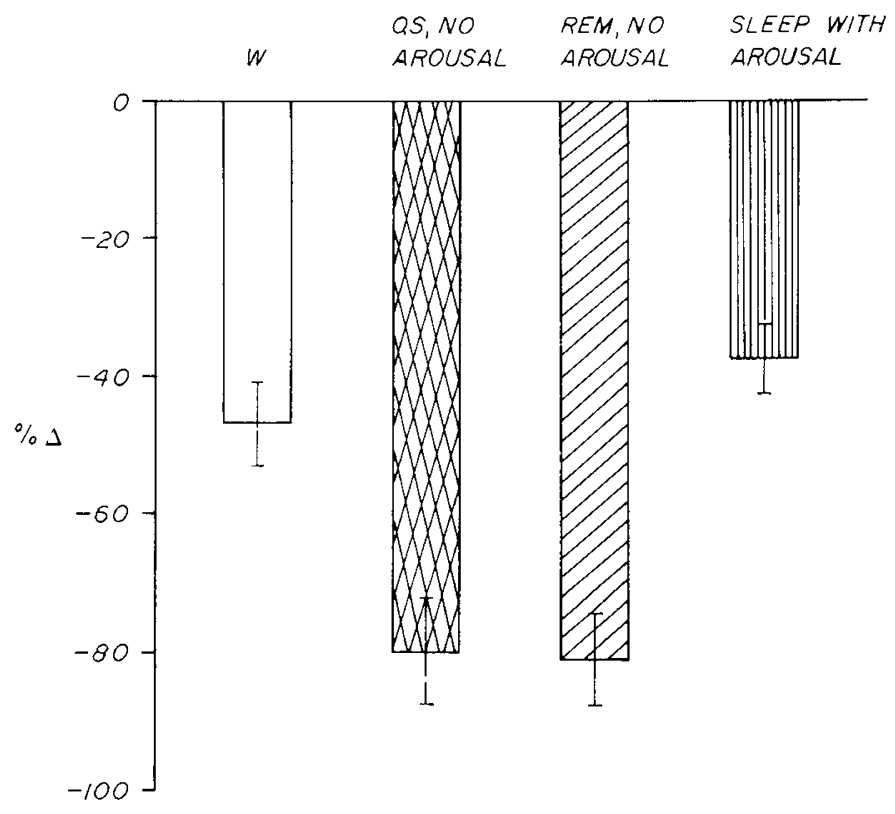

Fig. 2. Effect of arousal from sleep on the respiratory response to laryngeal chemoreflex stimulation. Tests associated with arousal were separated from those with continued sleep. Comparison of response in different activity states: $\mathrm{F}$ ratio $=42.8, P<0.001$. Response in wakefulness or sleep with arousal compared with quiet or REM sleep: $\mathrm{LSD}=21.0, P$ $<0.001$.

lamb was also studied for 3 subsequent wk, and although spontaneous recovery occurred normally by the fourth wk of age during $\mathrm{W}$, the need for resuscitation remained frequent following LCR stimulation during sleep (Fig. 3). Although resuscitation was needed more often during REM sleep, there was not a significantly higher incidence than during quiet sleep.

Cardiovascular response. (1) Heart rate. In all aciivity states, there was a significant bradycardia for $30 \mathrm{sec}$ after the onset of stimulation. There was no difference in the \% change in heart rate at $10 \mathrm{sec}$ among W (34.5\%), QS (37.8\%) and REM (42.0\%); however, bradycardia was more pronounced at 20 and $30 \mathrm{sec}$ for both quiet and REM sleep as compared to W $(P<0.05)$. Arousal from quiet or REM sleep resulted in a faster return to baseline heart rate, identical to that observed during W (Fig. 4). (F ratios for comparison of responses during different activity states at 20 and $30 \mathrm{sec}$ were $10.14, P<0.01$ and $10.79, P<0.01$ respectively with LSD of 14.7 and 12.8.)

Cardiovascular response. (2) Blood pressure. In all activity states, there was a significant rise in blood pressure after LCR stimulation. (Figure 5 and 6). The systolic blood pressure response was not found to be different among W, QS, REM at 10, 20, or $30 \mathrm{sec}$ although there was a trend for higher change during REM sleep 


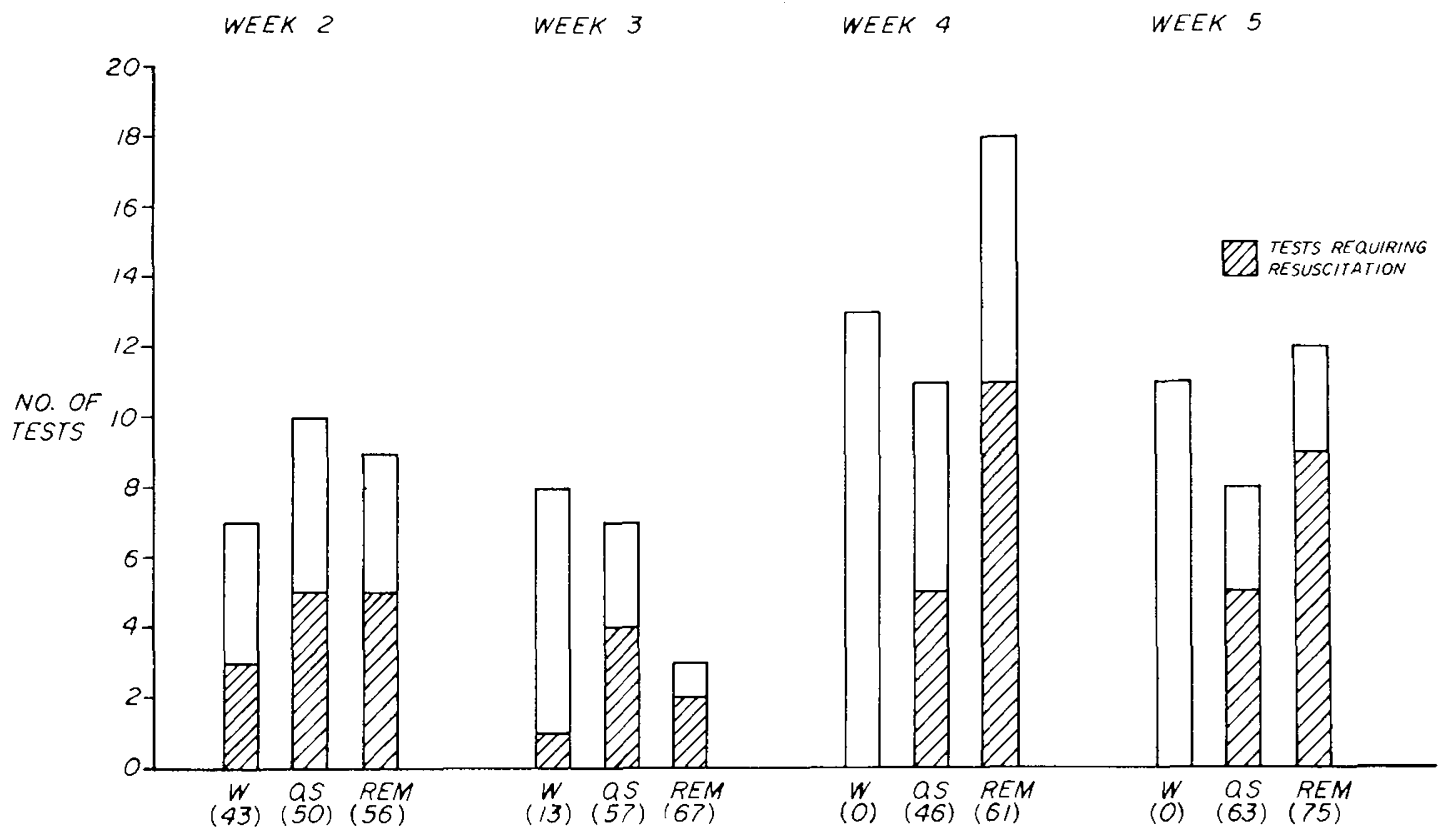

Fig. 3. Incidence of laryngeal chemoreflex stimulations requiring resuscitation with mechanical ventilation in a lamb studied repeatedly during the first 5 wk of life. During the 4th and 5th wk, resuscitation was no longer required during wakefulness but was still often needed during sleep.

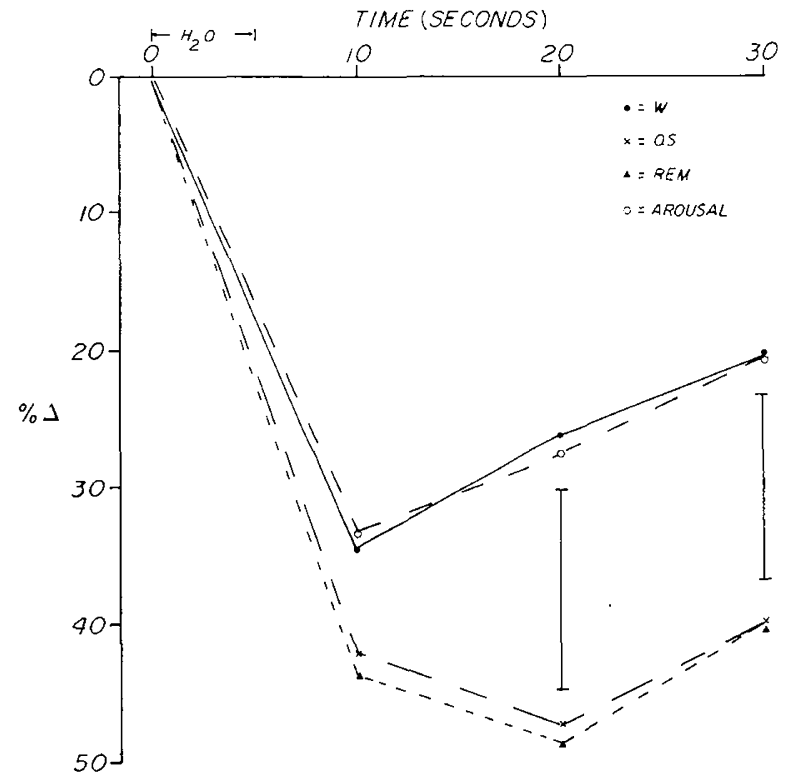

Fig. 4. Heart rate response to laryngeal chemoreflex stimulation expressed as \% change from baseline. Stimulation was performed during different activity states. Responses associated with arousal were plotted separately from those with continued sleep. Water was infused during 5 $\mathrm{sec}$ as indicated on the time scale. Heart rate responses during each activity state at 10,20, and $30 \mathrm{sec}$ after onset of stimulation were compared. F ratios were $2.57(\mathrm{NS}), 10.14(P<0.01)$, and $10.79(P<0.01)$, respectively. LSD is represented with vertical bars and indicate a significant difference for REM or QS compared to $\mathrm{W}$ or arousal $(P<0.05)$.

at 20 and $30 \mathrm{sec}$ ( $\mathrm{F}$ ratios were $0.19, \mathrm{NS}, 1.35$, NS, and 1.78, NS, respectively) (Fig. 5).

The same trend was found for the diastolic blood pressure response that was found to be significantly higher during REM sleep at $30 \mathrm{sec}(\mathrm{F}$ ratios were $0.73, \mathrm{NS}, 1.35$, NS, and $5.65, P<$ 0.05 respectively. $\mathrm{LSD}=11.7$ at $30 \mathrm{sec}, P<0.05$ ) (Fig. 6).

Arousal was associated with a faster return to baseline value during REM sleep.

Cardiovascular response. (3) Blood gases. Arterial blood gasses

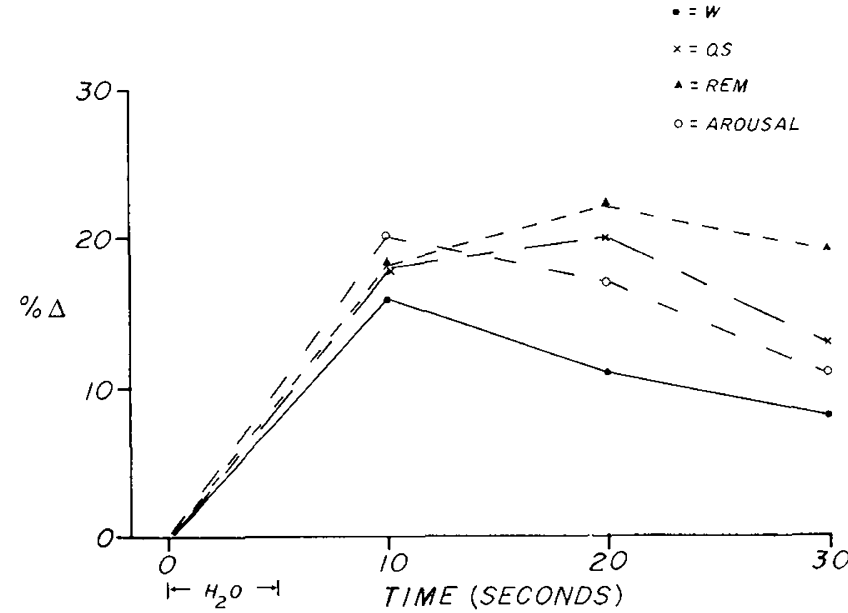

Fig. 5. Systolic blood pressure response to laryngeal chemoreflex stimulation expressed as \% change from baseline. Stimulation was performed during different activity states. Responses associated with arousal were plotted separately from those with continued sleep. Water was infused during $5 \mathrm{sec}$ as indicated on the time scale. Blood pressure responses during each activity state at 10,20 , and $30 \mathrm{sec}$ after onset of stimulation were compared. F ratios were 0.19 (NS), 1.35 (NS), and 1.78 (NS), respectively.

were measured in two lambs, $20 \mathrm{sec}$ after the onset of stimulation and illustrate the impaired recovery from apnea during sleep. During quiet and REM sleep, mean $\mathrm{PaO}_{2}$ after LCR stimulation is lower $(27.3 \pm 0.8,27.5 \pm 2.2$ torr: mean \pm S.E. $)$ and mean $\mathrm{PaCO}_{2}$ higher $(35.5 \pm 3.3,42.5 \pm 5.3$ torr) as compared to $\mathrm{W}$ $\left(\mathrm{PaO}_{2}=46.3 \pm 0.9, \mathrm{PaCO}_{2}=26.3 \pm 2.6\right.$ torr $), P<0.05$.

\section{DISCUSSION}

This study demonstrates the vulnerability of premature newborn lambs in either quiet or REM sleep to laryngeal chemoreflex stimulation. This is particularly true when it fails to induce arousal, thus leading to a delay in or failure to recover. Prolonged apnea during sleep is associated with more active vasoconstriction and 


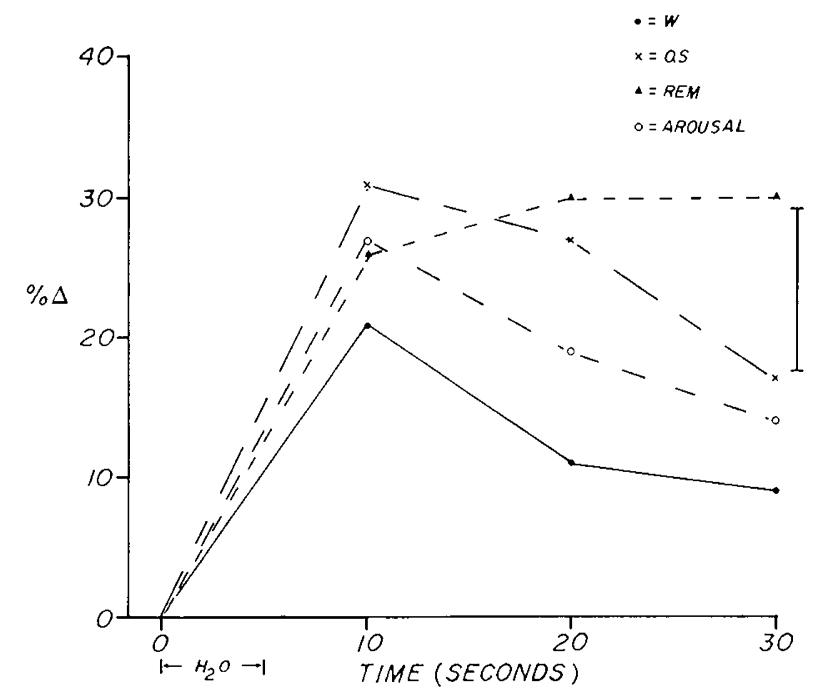

Fig. 6. Diastolic blood pressure response to laryngeal chemostimulation expressed as \% change from baseline. Stimulation was performed during different activity states. Responses associated with arousal were plotted separately from those with continued sleep. Water was infused during $5 \mathrm{sec}$ as indicated on the time scale. Blood pressure responses during each activity state at 10,20 , and $30 \mathrm{sec}$ after onset of stimulation were compared. F ratios were $0.73(\mathrm{NS}), 1.35(\mathrm{NS})$, and $5.65(P<0.05)$, respectively. At $30 \mathrm{sec}, \mathrm{LSD}$ was 11.7 indicating a significantly greater response in REM compared to other activity states $(P<0.05)$.

a greater reduction in cardiac output as indicated by prolonged hypertension and bradycardia.

The marked variation in the response among lambs during sleep is partly explained by a different incidence of arousal. A great variation is, however, also observed during wakefulness, which could be explained by a different sensitivity of the laryngeal chemoreceptors and/or of the carotid bodies among the lambs. This individual susceptibility has also been reported by others ( 25 , 26).

The heart rate response is immediate and pronounced in unanesthetized animals. It was greater at $10 \mathrm{sec}$ during sleep than during wakefulness, although this difference did not achieve statistical significance. The bradycardia measured at 20 and $30 \mathrm{sec}$ is parallel to the respiratory recovery. The heart rate changes appear also to be related to the cessation of breathing movements. We have previously demonstrated that the cardiovascular response is partially secondary to the resulting apneic asphyxia with stimulation of the arterial chemoreceptors (19), which are allowed to influence the heart and the vasculature without interaction from the pulmonary inflation reflex (1).

Systemic hypertension occurs in all activity states in response to reflex stimulation and is proportional to the duration of apnea. There is a trend for more sustained hypertension during sleep, particularly for diastolic hypertension during REM. This finding suggests that blood flow redistribution, which we (19) and others (21) previously have identified as a part of the LCR response in the awake lamb, also occurs during sleep.

Several mechanisms may explain the difference in the respiratory response to LCR stimulation among activity states.

The decreased respiratory drive during sleep, as indicated by a low mean inspiratory flow, could explain an impaired central ability to respond to asphyxia in those states.

A centrally mediated poststimulus respiratory inhibition has recently been advocated to explain the prolongation of apnea beyond the duration of the stimulus induced by superior laryngeal nerve stimulation in anesthetized newborn piglets (30). The possible influence of behavioral states on such a mechanism is so far unknown.

The importance of activity states in the control of vagaly induced reflex apnea has been reported by Frankstein (15). In chronically instrumented cats, apnea resulting from the stimulation of the central extremity of the severed vagus was found to be more pronounced during sleep, although quiet sleep was not differentiated from REM sleep.

A difference in the degree of apnea and arousal response during quiet and REM sleep was not seen in our group of lambs, although one lamb had a greater incidence of arousal during REM than during quiet sleep. Another lamb, which was studied for $4 \mathrm{wk}$, appeared more vulnerable during the 4th and 5 th wk to prolonged apnea during REM sleep and required resuscitation more often during REM than during quiet sleep, but this difference did not achieve statistical significance (Fig. 3).

One might have expected to see a more prolonged apnea and lower incidence of arousal in REM than in QS sleep. In REM sleep, when compared to quiet sleep, more prolonged apnea and a depressed arousal response to laryngeal stimulation (47), hypercapnia (39) and hypoxia (40) have been reported in studies performed on adult dogs. During REM sleep there is an inhibition of brainstem respiratory neurons, (38) and sensory afferents (3). In infants, a higher frequency of apneic episodes, which also last longer, has been observed in REM sleep $(12,17,18,45)$. This activity state is associated with inefficient ventilation due to ribcage collapse in premature infants and newborn lambs $(23,27)$, reduced thoracic gas volume $(23)$, depressed proprioceptive and chemoreceptive reflexes $(23,28,50)$ and it has been implicated in the etiology of SIDS (49).

On the other hand, an increased respiratory rate, minute volume and inspiratory pressure at one-tenth of a sec after airway occlusion have been found in REM, when compared to quiet sleep, which may represent an increased central drive in REM sleep (14). Guilleminault et al. (20) observed the worst apneic episodes (longest duration and greatest oxygen desaturation), not during REM sleep, but always in quiet or indeterminate sleep. Central hypoventilation in infants at risk for SIDS has also been reported (44). The possible importance of quiet sleep as a vulnerable period of central nervous regulation to the etiology of SIDS has also been stressed by Gould et al. (18). Baker and McGinty (2) have shown that active (REM) and not quiet sleep protects kittens against hypoxic cardiorespiratory failure. There is, therefore, ample evidence to indicate that both quiet and REM sleep are vulnerable states for apnea in the newborn period, although different mechanisms may exist that turn apnea episodes on, as well as off, in the different activity states. As this study shows, the mechanisms that turn off apnea (18) are not fully developed in the prematurely delivered newborn lamb in either state.

Henderson-Smart and Read found a greater incidence of arousal in quiet than in REM sleep during airway occlusion in premature newborn lambs (23). This form of apnea stimulus is, however, different from LCR stimulation and partially mediated through the vagal nerve. Vagal stimulation has been shown to lead to a shorter apnea without the poststimulus apnea or prolonged respiratory inhibition, which is observed following superior laryngeal nerve stimulation (30).

Postnatal maturation appears to be an important factor in the control of laryngeal chemoreflex-induced apnea. It has been shown that the respiratory response to LCR stimulation in newborn animals such as lambs, kittens, and monkeys is markedly diminished in the adult of the same species $(22,32,33,48)$. The observation made in one of our lambs, that failure to recover during the 2 nd wk after birth disappeared by wk 4 during wakefulness, agrees with an age-related effect. The influence of age on apnea induced by the "diving reflex" has also been reported in monkeys (16).

The role of the carotid bodies in the apneic and arousal response to laryngeal chemoreflex stimulation is, as yet, only speculative. Philipson et al. have, however, demonstrated their role in mediating the arousal response to hypoxia (7) and airway occlusion (8) during sleep. It is possible that the carotid bodies also mediate arousal during laryngeal chemostimulation. The functional maturity and integrity of this organ could, therefore, greatly influence the response to laryngeal reflex stimulation during sleep. A de- 
creased hypoxic ventilatory response in newborn lambs when compared to adults have been reported by Purves (41) and Belenky et al. (4). A decreased sensitivity to cyanide was found by Reynolds and Mackie (42). Malfunctioning carotid bodies have been implicated as an etiology for SIDS. Abnormalities of size (36) and ultrastructure (10) of carotid bodies from SIDS victims have been reported, as well as abnormal hypercarbic and hypoxic arousal responses in "near miss" SIDS children (34).

A role for the laryngeal chemoreflex itself in the pathogenesis of SIDS has been described in infants with gastroesophageal reflux $(24,31)$. Whether or not SIDS is secondary to LCR stimulation, most deaths occur during the night when the infants presumably are sleeping. This animal study shows the susceptibility of the young lamb during sleep to prolonged reflex apnea without arousal.

Unpublished data from our institution have shown that apnea from laryngeal chemoreflex stimulation can be reproduced in premature babies. Although LCR stimulation secondary to gastroesophageal reflux has not yet been documented as a cause of apnea in premature babies, several other types of stimuli such as cold oxygen blown on the face (9), nasopharyngeal suction (11) or orogastric feeding (37), are known to induce similar reflex apnea. Such stimulation may be more likely to induce profound apnea during sleep, which is the predominant behavioral state of these infants.

\section{REFERENCES AND NOTES}

1. Angell James, J. E. and DeBurgh Daly, M.: Cardiovascular responses in apnaeic asphyxia: role of arterial chemoreceptors and the modification of their effects by a pulmonary vagal inflation reflex. J. Physiol., 201: 87 (1969)

2. Baker T. L. and McGinty, D. J.: Reversal of cardiopulmonary failure during active sleep in hypoxic kittens. Implications for sudden infant death. Science, 198: 419 (1977)

3. Baldissera, F., Broggi, G., and Mancia, M.: Presynaptic inhibition of trigeminal afferent fibers during the rapid eye movements of desynchronized sleep. Experientia (Basel), 22: 754 (1966).

4. Belenky, D. A., Standaert, T. A., and Woodrum, D. E.: Maturation of hypoxic ventilatory response of the newborn lamb. J. Appl. Physiol. Respirat. Environ. Exercise Physiol., 47: 927 (1979).

5. Boushey, H. A., Richardson, P. S., and Widdicombe, J. G.: Reflex effects of laryngeal irritation on the pattern of breathing and total lung resistance. $J$. Physiol. (London), 224: 501 (1972).

6. Boushey, H. A., Richardson, P. S., Widdicombe, J. G., and Wise, J. C. M.: The response of laryngeal afferent fibres to mechanical and chemical stimuli. $J$. Physiol., 240: 153 (1974).

7. Bowes, G., Townsend, E. R., and Phillipson, E. A.: Effect of carotid body denervation on the arousal response to hypoxia in sleeping dogs. Physiologist, 23: 138 (1980).

8. Bowes, G., Townsend, E. R., Bromley, S. M., Kozar, L. F., and Phillipson, E. A.: Role of the carotid body and of afferent vagal stimuli in the arousal response to airway occlusion in sleeping dogs. Am. Rev. Respir. Dis., I23: 644 (1981).

9. Brown, W. U., Ostheimer, G. W., Bell, G. C., and Datta, S. S.: Newborn response to oxygen blown over the face. Anesthesiology, 44: 535 (1976)

10. Cole, S., Lindenberg, L. B., Galioto, F. M., Howe, P. E., DeGraff, A. C., Davis, J. M., Lubka, R., and Gross E. M.: Ultrastructural abnormalities of the carotid body in sudden infant death syndrome. Pediatrics, 63: 13 (1979).

11. Cordero, L. Jr. and Hon, E.: Neonatal bradycardia following nasopharyngeal stimulation. J. Pediatr., 78: 441 (1971).

12. Daily, W. J. R., Klaus, M., and Meyer, H. B. P.: Apnea in premature infants: monitoring incidence heart rate changes, and an effect of environmental temperature. Pediatrics, 43: 510 (1969).

13. Downing, S. E. and Lee, J. C.: Laryngeal chemo sensitivity, a possible mechanism for sudden infant death. Pediatrics, 55: 640 (1975).

14. Finer, N. N., Abrambs, I., and Taeush, H. W.: Ventilation and sleep states in newborn infants. J. Pediatr., 89: 100 (1976).

15. Frankstein S. I.: Neural Control of Respiration. In: Ruth Porter, Ed: CIBA Foundation Symposium: Breathing: Hering Breuer Centenary Symposium, pp. 53-58 (London, J. \& A. Churchill, Ltd., (1970).

16. French, M. D., Morgan, B. G., and Guntheroth, W. G.: Infant monkeys-a model for crib death. Am. J. Dis. Child., 123: 480 (1972).

17. Gabriel, M., Albani, M., and Schulte, F. J.: Apneic spells and sleep states in preterm infants. Pediatrics, 57: 142 (1976)

18. Gould, J. B., Lee, A. F., James, O., Sander, L., Taeger, H., and Fineberg, N.: The sleep state characteristics of apnea during infancy. Pediatrics, 59: 182 (1977).

19. Grogaard, J., Sundell, H., and Stahlman, M. T.: The cardiovascular response to laryngeal chemoreflex stimulation in newborn lambs. Pediatr. Res., 14: 445 (1980).
20. Guilleminault, C., Peraita, R., Souquet. M., and Dement, W. C.: Apneas during sleep in infants: possible relationship with sudden infant death syndrome. Science, 190: 677 (1975)

21. Harding, R., Johnson, P., Johnston, B. E., McClelland, M. F., and Wilkinson, A. $R$.: Cardiovascular changes in newborn lambs during apnea induced by stimulation of laryngeal receptors with water. J. Physiol., 256: 35P (1976).

22. Harding, R., Johnson, P., and McClelland, M. E.: Liquid-sensitive laryngeal receptors in the developing sheep, cat and monkey. J. Physiol., 277: 409 (1978).

23. Henderson-Smart, D. J. and Read, D. J. C.: Depression of intercostal and abdominal muscle activity and vulnerability to asphyxia during active sleep in the newborn. In: Guilleminault, C. and Dement, W. C., Eds: Sleep Apnea Syndromes. pp. 93-117 (Alan R. Liss, Inc, New York, 1978).

24. Herbst, J. J., Book, L. S., and Bray, P. F.: Gastroesophageal reflux in the "nearmiss" sudden infant death syndrome. J. Pediatr., 92: 73 (1978).

25. Johnson, P., Dawes, G. S., and Robinson, J. S.: Maintenance of breathing in newborn lambs. Arch. Dis. Child., 47: 151 (1972).

26. Johnson, P., Robinson, J. S., and Salisbury, D.: The onset and control of breathing after birth. In: Comline R. S. Ed: Foetal and Neonatal Physiology. p. 217 (Cambridge University Press, 1973).

27. Knill, R., Andrews, W., Bryan, A. C., and Bryan, M. H.: Respiratory load compensation in infants. J. Appl. Physiol. 40: 357 (1976).

28. Knill, R., and Bryan, A. C.: An intercostal-phrenic inhibitory reflex in human newborn infants. J. Appl. Physiol., 40: 352 (1976)

29. Kovar, I., Selstam, U., Catterton, W. Z., Stahlman, M. T., and Sundell, H. W.: Laryngeal chemoreflex in newborn lambs: Respiratory and swallowing response to salt, acids, and sugars. Pediatr. Res., I3: 1144 (1979).

30. Lawson, E. E.: Prolonged central respiratory inhibition following reflex-induced apnea. J. Appl. Physiol.: Respirat. Environ. Exercise Physiol., 50: 874 (1981).

31. Leape, L. L., Holder, T. M., Franklin, J. D., Amoury, R. A., and Ashcraft, K. W.: Respiratory arrest in infants secondary to gastroesophgeal reflux. Pediatrics, 60: 924 (1977).

32. Lucier, G. E.. Daynes, J., and Sessle, B. J.: Laryngeal Reflex Regulation: Peripheral and central neural analyses. Exp. Neurol., 62: 200 (1978).

33. Lucier, G. E., Storey, A. T., and Sessle, B. J.: Effects of upper respiratory tract stimuli on neonatal respiration: Reflex and single neuron analyses in the kitten. Biol. Neonate, 35: 82 (1979).

34. McCulloch, K., Brouillette, R. T., Guzzetta, A. J., and Hunt, C. E.: Abnormal hypercarbic and hypoxic arousal response in near-miss (N-M) SIDS. Pediatr. Res., 15: 726 (1981).

35. Milic-Emili. J.: Recent advances in the evaluation of respiratory drive. Int Anesthesiol. Clin., 15: 39 (1977).

36. Naeye, R. L., Fisher, R., Ryser, M., and Whalen, P.: Carotid body in the sudden infant death syndrome. Science, 191: 567 (1976).

37. Odell, G.: In: Klaus M. H. and Fanaroff A. A., Eds: Care of The High Risk Neonate, p. 147 (Saunders ed. Philadelphia, 1973).

38. Orem, J., Montplaisir, J., and Dement, W. C.: Changes in the activity of respiratory neurons during sleep. Brain Res., 82: 309 (1974).

39. Phillipson, E. A., Kozar, L. F., Rebuck, A. S., and Murphy, E.: Ventilatory and waking responses to $\mathrm{CO}_{2}$ in sleeping dogs. Am. Rev. Respirat. Dis., 115: 251 (1977).

40. Phillipson, E. A., Sullivan, C. E., Read, D. J. C., Murphy, E., and Kozar, L. F. Ventilatory and waking responses to hypoxia in sleeping dogs. J. Appl. Physiol.: Respirat. Environ. Exercise Physiol., 44: 512 (1978).

41. Purves, M. J.: The effects of hypoxia in the newborn lamb before and after denervation of the carotid chemoreceptors. J. Physiol., 185: 60 (1966).

42. Reynolds, S. R. M. and Machie, J. D.: Development of chemoreceptor response sensitivity: Studies in fetuses, lambs and ewes. Am. J. Physiol., 201: 239 (1961)

43. Rosenthal, I: Die Athembewegungen und ihre Beziehungen zum Nervus Vagus (August Hirschwald, Berlin, 1862) cited by Breuer, J.: Self-steering of Respiration Through the Nervus Vagus. In: Porter R., Ed.: CIBA Foundation Symposium. Breathing: Hering Breuer Centenary Symposium. pp. 359-394 (J \& A Churchill, London, 1970)

44. Shannon, D. C., Kelly, D. H., and O'Connell, K.: Abnormal regulation of ventilation in infants at risk for sudden-infant-death syndrome. New Engl. J. Med., 297: 747 (1977).

45. Steinschneider, A.: Prolonged sleep apnea and respiratory instability: A discriminative study. Pediatrics, 59: 962 (1977).

46. Storey, A. T. and Johnson, P.: Laryngeal water receptors initiating apnea in the lamb. Exp. Neurol., 47: 42 (1975).

47. Sullivan, C. E., Murphy, E., Kozar, L. F., and Phillipson, E. A.: Waking and ventilatory responses to laryngeal stimulation in sleeping dogs. J. Appl. Physiol.: Respirat. Environ. Exercise Physiol., 45: 681 (1978).

48. Sutton, D., Taylor, E. M., and Lindeman, R. C.: Prolonged apnea in infant monkeys resulting from stimulation of superior laryngeal nerve. Pediatrics, 61 : $519(1978)$

49. Tonkin, S.: Sudden infant death syndrome: Hypothesis of causation. Pediatrics, 55: $650(1975)$

50. Thoman, E. B., Freese, M. P., Becker, P. T., Acebo, C., Morin, V. N., and Tynan, W. D.: Sex differences in the ontogeny of sleep apnea during the first year of life. Physiol. Behav., 20: 699 (1978).

51. The present address of Francois Marchal: Maternite Regionale "A. Pinard”, Rue du Docteur Heydenreich, 54042 Nancy Cedex. France.

52. The present address of Barry C. Corke: The University of North Carolina at Chapel Hill, School of Medicine, Department of Anesthesiology, Chapel Hill, N.C. 27514.

53. The authors thank Dr. Mildred T. Stahlman for her support and encouragement 
and Patricia Minton, R.N. and Rao Gaddipati, Research Assistant for their helpful technical assistance, Dr. Alastair A. Hutchinson and Dr. Arlene Hutchison for their advice and discussion.

54. Requests for reprints should be addressed to: Dr. Hakan Sundell, Dept. of Pediatrics, Vanderbilt University Medical School, Nashville, TN 37232.
55. This research was supported by grants from the National Institute of Child Health and Human Development (No. HD10454) and March of Dimes Birth Defects Foundation (No. 1-739).

56. Received for publication October 20, 1981.

57. Accepted for publication February 3, 1982.

Copyright (C) 1982 International Pediatric Research Foundation, Inc

Printed in U.S.A. $0031-3998 / 82 / 1608-0621 \$ 02.00 / 0$ 